\title{
Effect of Freeze, Oven and Microwave Pretreated Oven Drying on Color, Browning Index, Phenolic Compounds and Antioxidant Activity of Hawthorn (Crataegus orientalis) Fruit
}

\author{
Hacer COKLAR*, Mehmet AKBULUT, Semih KILINC, Ali YILDIRIM, \\ Iliasu ALHASSAN
}

\begin{abstract}
University of Selcuk, Faculty of Agricultural, Department of Food Engineering, Ardicl Street, 42035, Selcuklu, Konya, Turkey; hacercoklar@selcuk.edu.tr(correspondingauthor);makbulut@selcuk.edu.tr; semihkilinc28@gmail.com; ayldrm.gm@gmail.com; hassanyass61@yahoo.com
\end{abstract}

\begin{abstract}
Flowers, leaves and fruits of hawthorn plant are traditionally used for treating diseases like hypertension and atherosclerosis. The medicinal effects of the plant are generally attributed to its phenolic compounds. However, the fruits are perishable materials because of their high content of water, and generally dried and stored to be used outside its season. The main aim of this research was to investigate the effect of different drying methods on phenolic compounds of the hawthorn fruit. Fruits were collected from the wild growing trees in Turkey. De-seeded fruits were dried in freeze-, oven- $\left(60^{\circ} \mathrm{C}\right)$ and microwave pretreated oven drying (microwave application for $5 \mathrm{~min}$ at $360 \mathrm{~W}$ before drying at $60^{\circ} \mathrm{C}$ ) methods and analyzed for antioxidant activity, phenolic compounds, total phenolic content and color parameters. Total phenolic content of fresh hawthorn fruits was found as $13.36 \mathrm{mg} \mathrm{g}^{-1} \mathrm{DW}$. Oven- and microwave pretreated oven drying methods had a reductive effect on total phenolic content and antioxidant activity of fruits when compared to freeze drying method. (-)-Epicatechin (994.10 $\left.\mathrm{mg} \mathrm{kg}{ }^{-1} \mathrm{DW}\right)$, rutin $\left(765.30 \mathrm{mg} \mathrm{kg}^{-1} \mathrm{DW}\right)$, and procyanidin $\mathrm{B} 2\left(553.80 \mathrm{mg} \mathrm{kg}^{-1} \mathrm{DW}\right)$ were the main phenolics of the fruit. Lowest values of these three compounds were observed in oven-dried fruits. Microwave pretreatment oven drying method resulted in browner product. Although the highest phenolic concentration and antioxidant activity were occurred in freezedried sample, microwave pretreatment before oven drying could be applied to reduce the time and cost of drying in terms of phenolic compounds and antioxidant activity.
\end{abstract}

Keywords: ABTS; browning index; color parameters $\left(L^{*}, a^{*}, b^{*}, C^{*}, b\right)$; Crataegus orientalis; DPPH; phenolic compounds Abbreviations: ABTS - 2,2'-azino-bis(3-ethylbenzothiazoline-6-sulphonic acid antioxidant activity; DPPH - 1,1-diphenyl-2picrylhydrazyl antioxidant activity; DW - dried weight; $C^{*}$ - Chroma; $b$ - $b u e$ angle.

\section{Introduction}

Crataegus orientalis, a member of Rosaceae family, is a kind of hawthorn with dark yellow:orange colored fruit that naturally grow in Mediterranean Basin, Turkey, Iran and other countries (Edward et al., 2012). Fruits, leaves and flowers of Crataegus plant are rich in phenolic compounds (García-Mateos et al., 2013a; García-Mateos et al., 2013b) and are traditionally used for cardiovascular disorders, hypertension and atherosclerosis treatments (Nabavi et al., 2015). Biological impacts of hawthorn plant are generally attributed to its phenolic compounds and antioxidant activity (Nabavi et al., 2015).
Polyphenols are antioxidant effective compounds and they possess higher free radical-scavenging activity than those of vitamins $\mathrm{C}$ and $\mathrm{E}$. While these vitamins are seen to have equal antioxidant activities with kaempferol, chlorogenic acid and caffeic acid, the antioxidant activities of epigallocatechin gallate, cyanidin, quercetin and rutin are approximately 2 to 5 times higher (Rice-Evans et al., 1997). Phenolic profile has an important role in antioxidant activities of fruits and vegetables as well as total phenolic concentration.

$(+)$-Catechin and (-)-epicatechin are flavan-3-ols in hawthorn fruit and generally (-)-epicatechin concentration is higher than (+)-catechin. Procyanidin B2, B5, C1 and D1 are the dimeric, trimeric and tetrameric flavan-3-ols detected in hawthorn fruit (Chang et al., 2006a; Nabavi et 
450

al., 2015). Hyperoside, apigenin, quercetin, chlorogenic acid, gallic acid, vitexin, hesperidin, coumaric acid, caffeic acid, naringenin and cratenacin are other phenolics of the fruit (Zhang et al., 2001; Liu et al., 2010; Kumar et al., 2012; Wen et al., 2015; Çoklar and Akbulut, 2016a; Çoklar and Akbulut, 2016b). Anthocyanins have been found in fruits of some Crataegus species such as Crataegus monogyna and Crataegus sinaica that have red colored fruits (Froehlicher $e t$ al., 2009; Kumar et al., 2012).

Fruits and vegetables are highly perishable foods due to their high water content and generally processed into dried products for several reasons such as prolonging their shelflife, enhancing storage stability, consuming after the seasons, reducing transport weight (Sagar and Kumar, 2010). On the other hand, method used in drying significantly affects quality of dried product such as rehydration capacity, color, and nutritional properties. Hot air-, oven-, sun-, and freezedrying methods are commonly used in drying of fruits and vegetable. Freeze drying is most effective method to protect the physical and chemical properties of fruits and vegetables. However it has disadvantages of being expensive and having long drying time (Ciurzyńska and Lenart, 2011). Especially, for the reasons of reducing drying time and energy consumptions and improving product quality, new drying technologies such as microwave and radio frequency have been developed for food products in recent years (VegaMercado et al., 2001). Furthermore, a large number of studies in fruits and vegetables drying have been performed on combining different drying methods to shorten drying rate, reduce energy consumption and improve product quality (Mejia-Meza et al., 2010; Chong et al., 2013; Wojdyło et al., 2014).

The aims of this study were to determine if there are changes in phenolic compounds, antioxidant activities and color of hawthorn fruit after drying with freeze drying, oven drying and microwave pretreated oven drying methods and to find out the best drying method for dried hawthorn fruit product in terms of color, phenolic compounds and antioxidant activity.

\section{Materials and Methods}

\section{Biologicalmaterial}

Crataegus orientalis fruits were collected from the wild growing trees in Beyşehir, Konya, Turkey (latitude $37^{\circ}$ 40' $\mathrm{N}$; longitude $31^{\circ} 43^{\prime} \mathrm{E}$ ) in the third week of September, 2015. Ripening period of the fruits was evaluated according to the skin color of fruit. The color of the hawthorn fruits used was dark yellow-orange. Fruits $(4 \mathrm{~kg})$ were cut into halves and seeds were removed before drying and microwave pretreatment.

\section{Drying methods}

De-seeded fruits were divided into four equal parts. One part was used as control sample to compare the effect of drying methods. And the others were dried in freeze-, oven and microwave pretreated oven dryers. For freeze-drying, 1 $\mathrm{kg}$ fruit was kept at $-18{ }^{\circ} \mathrm{C}$ in deep-freezer for $24 \mathrm{~h}$. Lyophilization of samples was carried out in a freeze dryer (Labogene ScanVac Coolsafe110-4, Lynge, Denmark).
Throughout drying operation, vacuum chamber pressure and condenser temperature were $2.0 \mathrm{mbar}$ and $-110{ }^{\circ} \mathrm{C}$, respectively.

For microwave pretreated oven drying method, microwaves were used to pretreat the fresh fruits in a microwave oven (Arçelik, MD 564) at $360 \mathrm{~W}$ for $5 \mathrm{~min}$. Pretreated fruits were spread on a tray and dried in oven drier (Nuve, Turkey) set at $60{ }^{\circ} \mathrm{C}$. For oven-drying, the fruits $(1 \mathrm{~kg})$ were spread on a tray and dried in an oven (Nuve, Turkey) at $60{ }^{\circ} \mathrm{C}$. Drying in all methods was completed when the products reached a dry matter of $95 \pm 1 \%$. Fruits were dried for $15.30,24$ and $72 \mathrm{~h}$ in microwave combined oven-, oven-, and freeze dryers, respectively.

\section{Chemicals}

HPLC grade acetonitrile and methanol were from Merck (Darmstadt, Germany). All chemicals were analytical grade and acquired from either Sigma Chemical Co. (St. Louis, MO) or Merck (Darmstadt, Germany). Gallic acid (PubChem CID : 370), protocatechuic acid (PubChem CID : 72), (+)-catechin (PubChem CID : 9064), (-)-epicatechin (PubChem CID : 72276), (-)epigallocatechin (PubChem CID : 72277), procyanidin B1 (PubChem CID : 11250133), procyanidin B2 (PubChem CID : 122738), chlorogenic acid (PubChem CID : 1794427), caffeic acid (PubChem CID : 689043), rutin (PubChem CID : 5280805), kaempferol-3-glucoside (PubChem CID : 5282102) were purchased from Extrasynthese (Genay, France).

\section{Analysis procedures \\ Extraction procedure}

One $\mathrm{g}$ of ground dried hawthorn fruit was extracted by using a homogenizer (WiseMixTM HG-150; Daihan Scientific, Korea) in $50 \mathrm{~mL}$ methanol:water (80:20) solvent mixture. Then, the extract was centrifuged (NF 800R, Nuve, Turkey) at $4100 \times \mathrm{g}$ for $10 \mathrm{~min}$. Supernatant was removed and put into a glass jar and residue was re-extracted with solvent mixture. Supernatants from two extractions were poured in a jar glass and stored at $-18{ }^{\circ} \mathrm{C}$ until further analyses.

\section{Analysis of total phenolic content}

The total phenolic contents of fresh and dried hawthorn fruit were determined by Folin-Ciocalteu procedure (Singleton and Rossi, 1965). The methanolic extract $(0.5$ $\mathrm{mL}$ ) was mixed with $2.5 \mathrm{~mL}$ Folin-Ciocaleu's reagent $(0.2$ $\mathrm{N})$ and $2.0 \mathrm{~mL}$ sodium carbonate $\left(75 \mathrm{~g} \mathrm{~L}^{-1}\right)$. Absorbance of the reaction mixtures was read against the blank at $765 \mathrm{~nm}$ after 120 min using a spectrophotometer (U-1800, Hitachi, Japan). Results were expressed as mg gallic acid equivalents (GAE) $\mathrm{g}^{-1} \mathrm{DW}$.

\section{Antioxidant Activity Analyses DPPH assay}

2,2-Diphenyl-1-picrylhydrazyl antioxidant activities of the fruits were determined according to the (BrandWilliams et al., 1995). Extract $(0.1 \mathrm{~mL})$ was added to 3.9 $\mathrm{mL}$ of a DPPH $\left(6 \times 10^{-5} \mathrm{M}\right)$ methanolic solution. After 30 min incubation at room temperature in the dark, the 
absorbance was measured at $515 \mathrm{~nm}$ by using a spectrophotometer. Results were expressed as mmol Trolox Equivalent (TE) $\mathrm{kg}^{-1} \mathrm{DW}$.

\section{ABTS assay}

The protocol, described by $\mathrm{Re}$ et al. (1999), was followed to determine the ABTS antioxidant activity of the extracts. The extract $(10 \mu \mathrm{L})$ was added to $990 \mu \mathrm{L}$ ABTS• solution, generated with potassium persulfate solution $(2.45$ $\mathrm{mM})$ and ABTS solution $(7 \mathrm{mM})$. The absorbance at 734 $\mathrm{nm}$ was measured after $6 \mathrm{~min}$ and the reduction in the absorbance was noted. Results were reported as mmol trolox equivalent (TE) $\mathrm{kg}^{-1} \mathrm{DW}$.

\section{Analysis of phenolic compounds}

Extracted phenolics from hawthorn fruit were purified before the HPLC analysis by using C18 SPE cartridges (Agilent, USA), preconditioned by passing water and methanol. The extract $(2 \mathrm{~mL})$ was loaded in the cartridges. Phenolics were eluted with methanol. Methanol eluate was evaporated at $35^{\circ} \mathrm{C}$, re-suspended in $1 \mathrm{~mL}$ methanol and then filtered through $0.45 \mu \mathrm{m}$ pore size syringe filter (Sartorius AG, Goettingen, Germany) (Coklar and Akbulut, 2017). The analysis of phenolic compounds in the extract was carried out by Agilent 1260 Infinity Series HPLC system equipped with diode array detector. Separation was achieved by a reverse phase C18 column ( 5 $\mu \mathrm{m}, 250 \times 4.6 \mathrm{~mm}$ i.d). Mobil phase consisted of acetic acid:water and water:acetonitrile:acetic acid, and the flow rate was $0.75 \mathrm{~mL} \mathrm{~min}^{-1}$. The detector was set at 280,320 and $360 \mathrm{~nm}$ for phenolics. The identification of phenolics was confirmed by comparing their retention times and UV spectra. The data analysis was performed by ChemStation software (Rev.B.04.03[16], Agilent, Waldbronn, Germany).

\section{Color measurement}

Reflectance color values $\left(L^{*}, a^{*}, b^{*}, C^{*}\right.$ and $\left.h\right)$ of dried and fresh hawthorn fruits were measured by using a spectrophotometer (CM-5, Konica Minolta, Osaka, Japan). Spectra magic NX Lite (CM-S100w, Konica Minolta Sensing Inc.) software was used in taking color values from the device. The bue angle $(b)$ and Chroma $\left(C^{*}\right)$ values were calculated using the equations below:

$$
\begin{aligned}
& h=\tan ^{-1} \frac{b *}{a *} \\
& C^{*}=\sqrt{a *^{2}+b *^{2}}
\end{aligned}
$$

Browning index (BI) was calculated from $L^{*}, a^{*}$ and $b^{*}$ values according to the following equation (Maskan, 2001):

$$
\begin{aligned}
& \mathrm{BI}=\frac{[(\mathrm{x}-0.31)]}{0.17} \\
& \text { Where, } \\
& \mathrm{x}=\frac{\left(a^{*}+1.75 L^{*}\right)}{\left(5.645 L^{*}+a^{*}-3.012 b^{*}\right)}
\end{aligned}
$$

\section{Statistical analysis}

Results were presented as means \pm standard deviations (SD) and subjected to one way analysis of variance
(ANOVA), at a confidence level of $95 \%$, to determine the effect of drying methods on total phenolic content, antioxidant activity, individual phenolic compounds and color. Duncan multiple range test were used in order to compare differences between the means. Pearson's correlation coefficients were calculated to estimate the correlation between phenolic compounds and antioxidant activities. Statistical analyses were performed by using MINITAB (Released 14, Minitab Inc. USA) and Mstat C (Mstat C, 1988) programs.

\section{Results and Discussion}

\section{Total phenolic content of fresh and dried fruits}

The results on total phenolic contents (TPC) of fresh and dried hawthorn fruits can be seen in Fig. 1. A decrease in TPC content of samples dried by using all the drying methods was observed as compared to the TPC value of the fresh sample (13.36 $\left.\mathrm{mg} \mathrm{GAE} \mathrm{g}^{-1} \mathrm{DW}\right)$. Losses in TPC of the fruit were $5.40,21.81$ and $27.53 \%$ in freeze-, microwave pretreated oven, and oven drying methods, respectively. While decreases of TPC in microwave pretreatment ovenand oven dried fruits were statistically significant, differences between fresh and freeze dried fruit was insignificant.

As reported in previous studies, drying methods have different effects on total phenolic amounts of fruits and vegetables (Kwok et al., 2004; Jing et al., 2010). As increases have been reported in total phenolic content of blueberries (Kwok et al., 2004), papaya (Annegowda et al., 2014), tomato (Chang et al., 2006), jujubes (Gao et al., 2012), sweet potato (Jing et al., 2010) after freeze drying; same amount of phenolics have been detected in freeze driedmuskmelon (Shofian et al., 2011) as compared with their fresh states. However, phenolic contents of starfruit, mango, papaya, watermelon, sour cherry have decreased by freezedrying (Shofian et al., 2011; Wojdyło et al., 2014).

Differences in the results of researches about the effect of drying on phenolic content have attributed factors such as drying method, extraction and analysis procedure. Differences in extraction procedure of phenolics, drying method and plant material have not been easy to compare this study to previous studies. On the other hand, Wojdyło et al. (2009) found out that freeze-dried and vacuum microwave-dried strawberries had the highest concentration of phenolic compounds than vacuum-dried and convectivedried strawberries. They pointed out that oxidative and thermal degradation of phenolic compounds due to the increasing heat treatment lead to decreases in phenolic compounds in convective dried fruits.

\section{Phenolic profile of fresh and dried hawthorn fruits}

We identified four phenolic acids (gallic, protocatechuic, chlorogenic, and caffeic acids), three monomeric $((+)$-catechin, (-)-epicatechin, and (-)-epigallocatechin gallate), and two dimeric (procyanidin B1 and procyanidin B2) flavan-3-ols, rutin and kaempferol-3-glucoside in hawthorn fruits as shown in Fig. 2. According to results, all phenolics detected in the fruit were affected by the drying methods (Table 1). The decreases recorded in amount of caffeic acid in three of the drying methods were found to be 


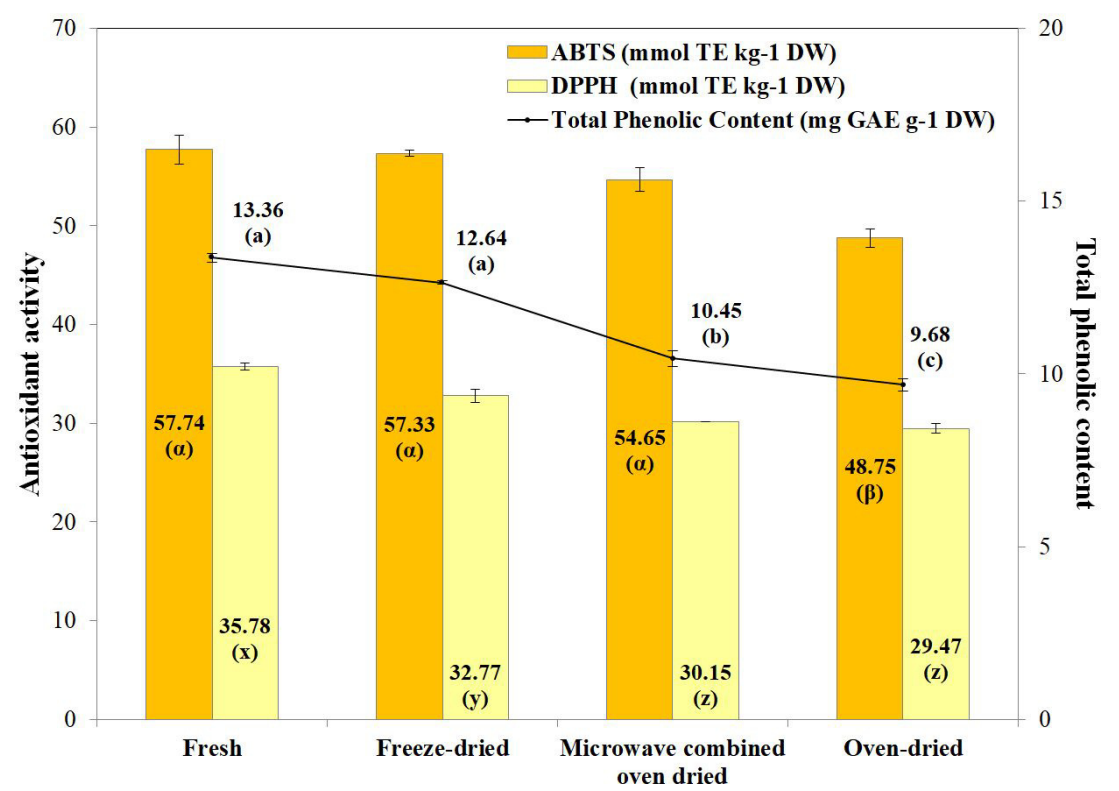

Fig. 1. Total phenolic content and antioxidant activities of fresh and dried hawthorn fruits (different letters and symbols within each antioxidant activity bar and phenolic content line indicate statistically significant differences $(\mathrm{p}<0.05))$

Table 1. Phenolic compounds of fresh and dried hawthorn fruits $\left(\mathrm{mg} \mathrm{kg}^{-1} \mathrm{DW}\right)$

\begin{tabular}{ccccc}
\hline \multirow{2}{*}{ Phenolic compounds } & \multicolumn{4}{c}{ Drying methods } \\
\cline { 2 - 5 } & Fresh & Freeze & Microwave pretreated oven & Oven \\
\hline Gallic acid & $24.23 \pm 021 \mathrm{c}$ & $37.19 \pm 1.27 \mathrm{a}$ & $32.44 \pm 0.04 \mathrm{~b}$ & $38.60 \pm 0.07 \mathrm{a}$ \\
Protocatechuic acid & $37.13 \pm 2.86 \mathrm{a}$ & $29.86 \pm 0.16 \mathrm{~b}$ & $16.50 \pm 0.59 \mathrm{c}$ & $29.48 \pm 0.28 \mathrm{~b}$ \\
Procyanidin B1 & $162.00 \pm 21.32 \mathrm{a}$ & $193.10 \pm 3.95 \mathrm{a}$ & $24.00 \pm 0.14 \mathrm{c}$ & $104.50 \pm 21.27 \mathrm{~b}$ \\
$(+)$-Catechin & $231.00 \pm 54.70 \mathrm{a}$ & $89.40 \pm 1.22 \mathrm{~b}$ & $100.60 \pm 0.01 \mathrm{~b}$ & $98.80 \pm 0.96 \mathrm{~b}$ \\
Procyanidin B2 & $553.80 \pm 13.23 \mathrm{a}$ & $488.40 \pm 27.51 \mathrm{a}$ & $378.20 \pm 37.92 \mathrm{~b}$ & $246.50 \pm 6.72 \mathrm{c}$ \\
(-)-Epicatechin & $994.10 \pm 4.40 \mathrm{a}$ & $946.80 \pm 15.27 \mathrm{~b}$ & $745.40 \pm 5.02 \mathrm{c}$ & $588.80 \pm 9.23 \mathrm{~d}$ \\
Chlorogenic acid & $223.30 \pm 1.02 \mathrm{~b}$ & $239.40 \pm 7.99 \mathrm{a}$ & $177.60 \pm 1.29 \mathrm{c}$ & $188.10 \pm 0.96 \mathrm{c}$ \\
Caffeic acid & $21.60 \pm 0.26$ & $19.15 \pm 2.81$ & $11.94 \pm 9.01$ & $17.64 \pm 0.15$ \\
(-)-Epigallocatechin gallate & $311.80 \pm 9.06 \mathrm{a}$ & $203.70 \pm 0.74 \mathrm{~b}$ & $164.70 \pm 1.09 \mathrm{c}$ & $137.00 \pm 1.56 \mathrm{~d}$ \\
Rutin & $765.30 \pm 18.47 \mathrm{a}$ & $591.10 \pm 79.30 \mathrm{~b}$ & $840.50 \pm 0.36 \mathrm{a}$ & $808.00 \pm 3.78 \mathrm{a}$ \\
Kaempferol-3-glucoside & $203.40 \pm 1.07 \mathrm{a}$ & $162.00 \pm 4.74 \mathrm{~b}$ & $163.00 \pm 3.67 \mathrm{~b}$ & $165.60 \pm 4.08 \mathrm{~b}$ \\
\hline Note: Results were given as mean \pm standard deviation $(\mathrm{n}=4)$. Different letters in the same row indicate statistically significant differences between drying methods (p $<$
\end{tabular}
$0.05)$.

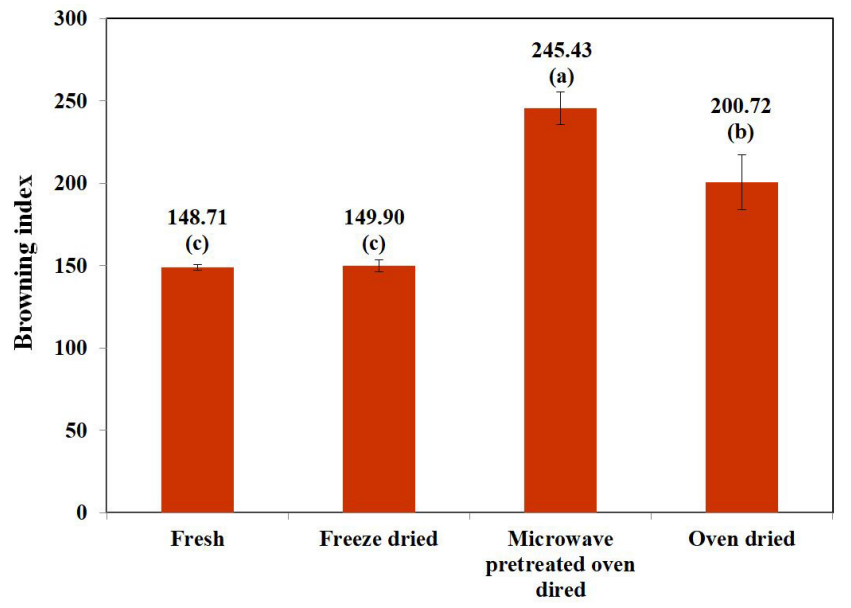

Fig. 2. Browning index of fresh and dried hawthorn fruits (different letters within each bar indicates statistically significant differences $(\mathrm{p}<0.05))$ statistically insignificant. The highest (-)-epicatechin amount was found in fresh fruit with $994.10 \mathrm{mg} \mathrm{kg}^{-1} \mathrm{DW}$. Freeze- and microwave pretreated oven dried fruits followed the fresh sample with 946.80 and $745.40 \mathrm{mg} \mathrm{kg}^{-1} \mathrm{DW}$ respectively, and lowest value was determined in oven dried sample (588.8 $\left.\mathrm{mg} \mathrm{kg}^{-1} \mathrm{DW}\right)$.

Similar to our result, decreases in catechin and epicatechin contents of oven dried apple (Joshi et al., 2011) and microwave dried sour cherry (Wojdyło et al., 2014) have been reported.

No statistically significant differences in the amounts of both procyanidin B1 and B2 were observed in fresh and freeze dried sample. However, catechin content of freeze dried fruit was lower than that of fresh sample. While lowest amount of procyanidin B1 was found in microwave pretreated oven dried sample $\left(24.0 \mathrm{mg} \mathrm{kg}^{-1} \mathrm{DW}\right)$, loss of procyanidin $\mathrm{B} 2$ was higher in oven dried method than that in microwave pretreated oven dried method.

Both oven- and microwave pretreated oven drying induced a decrease in chlorogenic acid content of fruit, with 
no differences between these two methods. However, chlorogenic acid concentration in freeze dried fruit was considerably higher than that of the fresh sample. Protocatechuic concentration in freeze-, microwave pretreated oven- and oven dried fruit found to be decreased by $19.58,55.56$ and $20.60 \%$, respectively. All the three drying methods had a destroying effect on kaempferol-3glucoside. Higher amounts of gallic acid were found in freeze-, oven- and microwave pretreated oven dried fruits as compared to fresh fruits.

In an accordance to our results, Joshi et al. (2011) reported that there was lower chlorogenic acid content in oven dried apple compared to fresh fruit. In a previous study, destructive effects of drying of jujube by using microwave-, oven- and freeze-dryer on protocatechuic acid has been reported (Gao et al., 2012). Miletić et al. (2013) also discovered that there was an increase in gallic acid concentration in plum after hot air drying.

Mohd Zainol et al. (2009) pointed out that losses in naringin, rutin, quercetin, catechin concentration of Centella asiatica after freeze-, vacuum-oven and air-oven drying could be as a result of temperature and time used in the drying techniques.

\section{Antioxidant activity of fruits}

Antioxidant activity results of fresh and dried hawthorn fruits by DPPH and ABTS assays are shown in Fig. 1. Fresh fruit possessed the highest DPPH value with $35.78 \mathrm{mmol}$ TE $\mathrm{kg}^{-1} \mathrm{DW}$. However, the DPPH value was decreased to $32.77,30.15$ and $29.47 \mathrm{mmol}$ TE $\mathrm{kg}^{-1} \mathrm{DW}$ after freeze-, oven-, and microwave pretreated oven drying, respectively. Although oven dried fruit was seemed to have the lowest DPPH value, differences between the values of oven- and microwave pretreated oven dried fruits were statistically insignificant. Considering all the drying methods in terms of DPPH value of the hawthorn fruit, freeze-drying has seen to be the most convenient method.

With regard to ABTS antioxidant activity, fresh fruit had the higher $A B T S$ value $\left(57.74 \mathrm{mmol} \mathrm{TE} \mathrm{kg}^{-1} \mathrm{DW}\right)$ than all the dried samples. Similar to DPPH antioxidant activity results, freeze-, oven- and microwave pretreated oven drying methods have led to reductions on ABTS value of the fresh fruit by approximately $0.72,5.35$ and $15.57 \%$, respectively.
However, the only method that reduced the ABTS value statistically significant was oven drying. Retention of antioxidant compounds was better in freeze-drying method when compared to other drying methods. However, taking into account the ABTS values, microwave pretreated oven drying method could be an alternative drying method to freeze-drying.

Previous studies have reported that decreases in antioxidant activity of jujube (Gao et al., 2012) and raspberry (Mejia-Meza et al., 2010) after oven drying; mango (Shofian et al., 2011), raspberry (Mejia-Meza et al., 2010), starfruit (Shofian et al., 2011), after freeze drying; apple (Chong et al., 2013), jujube, mango, papaya and pear (Gao et al., 2012) after microwave drying; and mango after freeze, cabinet, vacuum and infrared drying (Sogi et al., 2015).

As reported by Froehlicher et al. (2009), polyphenolic compounds, especially epicatechin, catechin, procyanidins, are one of the most effective antioxidant compounds of hawthorn fruits. Considering the decreases in total and individual polyphenolic compounds in freeze-, oven-, and microwave pretreated oven drying methods, it could be concluded that reduction in antioxidant activities of dried fruit resulted from the changes in phenolic compounds.

Although the hawthorn fruits contain non-phenolic antioxidant compounds such as vitamin C (García-Mateos et al., 2013a; Gundogdu et al., 2014), phenolic compounds are the main antioxidative effective compounds of the fruits. As seen in Table 2, correlation analysis results encouraged that antioxidant activity of hawthorn fruit aroused mostly from its phenolic compounds.

\section{Color values of hawthorn fruits}

The results of color measurement in dried and fresh fruits are shown in Table 3. Color is an important factor for consumers in food choice. Generally, acceptability of processed fruits and vegetables increases when their colors are close to original unprocessed ones. Therefore, in a dryer design for fruits and vegetables, color of the dried product is taken into consider. The $L^{*}$ value of fresh hawthorn fruit was higher than that of dried fruits, except freeze-dried sample. The results indicated that freeze drying was resulted in lighter colored products, even more than the fresh fruit.

Table 2. Correlation analysis between phenolic compounds and antioxidant activities in fresh and dried Hawthorn fruit

\begin{tabular}{|c|c|c|c|c|c|c|}
\hline \multirow{2}{*}{$\begin{array}{c}\text { Phenolic compounds } \\
\text { Gallic acid }\end{array}$} & \multicolumn{2}{|c|}{$\mathrm{DPPH}$} & \multicolumn{2}{|c|}{ Total Phenolic } & \multicolumn{2}{|c|}{ ABTS } \\
\hline & $-0.745^{\mathrm{a}}$ & $0.034^{\mathrm{b}}$ & -0.614 & 0.106 & -0.573 & 0.138 \\
\hline Protocatechuic acid & 0.696 & 0.055 & 0.627 & 0.096 & 0.186 & 0.660 \\
\hline Procyanidin B1 & 0.648 & 0.082 & 0.734 & 0.038 & 0.463 & 0.248 \\
\hline$(+)$-Catechin & 0.801 & 0.017 & 0.597 & 0.118 & 0.481 & 0.227 \\
\hline Procyanidin B2 & 0.919 & 0.001 & 0.946 & 0.000 & 0.908 & 0.002 \\
\hline (-)-Epicatechin & 0.908 & 0.002 & 0.977 & 0.000 & 0.924 & 0.001 \\
\hline Chlorogenic acid & 0.754 & 0.031 & 0.861 & 0.006 & 0.663 & 0.073 \\
\hline Caffeic acid & 0.571 & 0.139 & 0.464 & 0.246 & 0.123 & 0.772 \\
\hline (-)-Epigallocatechin gallate & 0.970 & 0.000 & 0.894 & 0.003 & 0.740 & 0.036 \\
\hline Rutin & -0.337 & 0.415 & -0.573 & 0.138 & -0.480 & 0.228 \\
\hline Kaempferol-3-glucoside & 0.831 & 0.011 & 0.639 & 0.088 & 0.415 & 0.307 \\
\hline DPPH & & & 0.931 & 0.001 & 0.766 & 0.027 \\
\hline Total Phenolic & & & & & 0.868 & 0.005 \\
\hline
\end{tabular}

${ }^{a}$ Pearson's correlation coefficient

${ }^{\mathrm{b}}$ Significance level 
454

Table 3. Reflectance color $\left(L^{*}, a^{*}, b^{*}, C^{*}\right.$ and $\left.h\right)$ values of fresh and dried hawthorn fruits

\begin{tabular}{cccccc}
\hline Sample & $L^{*}$ & $a^{*}$ & $b^{*}$ & $C^{*}$ & $b$ \\
\hline Fresh & $61.86 \pm 1.18 \mathrm{~b}$ & $11.65 \pm 0.26 \mathrm{~b}$ & $49.07 \pm 0.42 \mathrm{~b}$ & $50.56 \pm 0.41 \mathrm{~b}$ & $76.82 \pm 0.25 \mathrm{a}$ \\
Freeze dried & $74.61 \pm 1.78 \mathrm{a}$ & $15.82 \pm 0.89 \mathrm{ab}$ & $59.04 \pm 3.14 \mathrm{a}$ & $61.14 \pm 2.80 \mathrm{a}$ & $74.94 \pm 1.60 \mathrm{~b}$ \\
$\begin{array}{c}\text { Microwave pretreated } \\
\text { oven dried }\end{array}$ & $53.66 \pm 2.87 \mathrm{c}$ & $22.17 \pm 0.32 \mathrm{a}$ & $54.87 \pm 1.40 \mathrm{ab}$ & $59.19 \pm 1.18 \mathrm{a}$ & $67.93 \pm 0.81 \mathrm{c}$ \\
Oven dried & $47.30 \pm 0.93 \mathrm{~d}$ & $21.88 \pm 4.03 \mathrm{a}$ & $42.49 \pm 1.64 \mathrm{c}$ & $47.85 \pm 3.29 \mathrm{~b}$ & $62.84 \pm 3.36 \mathrm{c}$ \\
\hline
\end{tabular}

Note: Different letters in the same column indicate statistically significant differences between drying methods $(\mathrm{p}<0.05)$ and results, given as mean \pm standard deviation $(\mathrm{n}=4)$

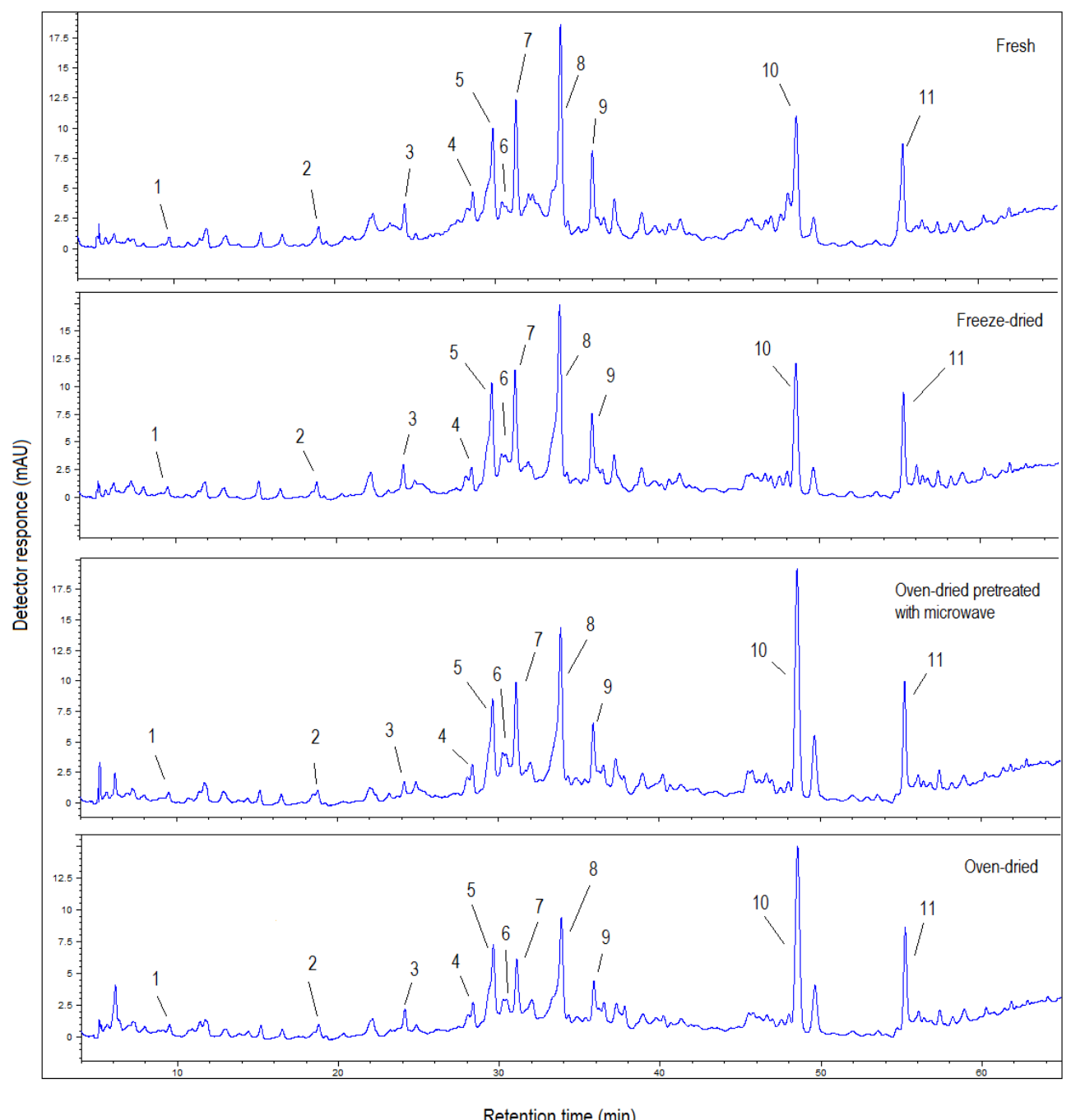

Fig. 3. HPLC chromatogram of hawthorn fruits detected at $280 \mathrm{~nm}$ (1: Gallic acid, 2: Protocatechuic acid, 3: Procyanidin B1, 4: (+)-Catechin, 5: Chlorogenic acid, 6: Caffeic acid, 7: Procyanidin B2, 8: (-)-Epicatechin, 9 (-)-Epigallocatechin gallate, 10: Rutin, 11. Kaempferol-3-glucoside)

The darkest colored product was obtained using oven dried method without any pretreatment. The $a^{*}$ value of the fruit increased with all drying methods. The lowest redness was determined in freeze dried fruit among other dried samples. $C^{*}$ value of fresh fruit increased after drying with freeze-, and microwave pretreated oven dryer. On the other hand, there was a statistically insignificant decrease in $C^{*}$ value of oven dried fruit when compared to fresh fruit. The lowest $h$ value was observed in oven dried sample. However difference between $h$ values of oven and microwave pretreated oven dried samples was statistically insignificant.
The $b^{*}$ value of fresh fruit increased from 49.07 to 59.04 and 54.87 in freeze-, and microwave pretreated oven dried samples, respectively.

Yanyang et al. (2004) determined higher $b$ values in air dried and microwave dried wild cabbage. Contrary to our results, in a study about drying of potato cubes by using microwave and hot air dryers, lower $b$ values were reported for microwave dried potatoes as compared to fresh and hot air dried potatoes (Bondaruk et al., 2007).

Krokida et al. (2001) reported that conventional and microwave combined conventional dryers generated more 
brown colored apples, bananas, potatoes and carrots than in freeze dryer.

The least $h$ value was found in oven-dried fruit. According to the results, microwave pretreated oven dried fruit had the highest browning index (Fig. 3). The browning in fruit after freeze drying was statistically insignificant. Similarly, Maskan (2001) has reported that browner kiwifruit produced after microwave drying than that of hot air drying. Color differences in fruits which were dried with different techniques could be attributed to the differences in chemical compositions of fruits, pretreatments before drying and variation in drying methods such as drying temperature, air velocity, and microwave power.

\section{Conclusions}

The results of this study indicated that drying of hawthorn fruit by freeze-, oven-, and microwave pretreated oven dryer caused significant changes in phenolic compounds, antioxidant activity and color. Freeze-drying resulted in the best quality product in terms of total phenolic content, individual phenolics, antioxidant activity and color values when compared to oven and microwave pretreated oven drying methods. Even though the drying time was reduced, microwave pretreatment made a negative effect on color of the fruit. This could be interpreted that microwave pretreatment oven drying produced higher quality products in the point of antioxidant activity and total phenolic content than that of oven-drying. Future works should focus on enhancing the quality of dried hawthorn fruit by applying different microwave powers and microwave radiation time.

\section{Acknowledgements}

This research was supported by TUBITAK-BIDEB undergraduate Scholarships programme with the project number 1919B011503245.

\section{References}

Annegowda H, Bhat R, Yeong KJ, Liong MT, Karim A, Mansor S (2014). Influence of drying treatments on polyphenolic contents and antioxidant properties of raw and ripe papaya (Carica papaya $L$.). International Journal of Food Properties 17(2):283-292.

Bondaruk J, Markowski M, Błaszczak W (2007). Effect of drying conditions on the quality of vacuum-microwave dried potato cubes. Journal of Food Engineering 81:306-312.

Brand-Williams W, Cuvelier ME, Berset C (1995). Use of a free radical method to evaluate antioxidant activity. LWT-Food Science and Technology 28(1):25-30.

Chang CH, Lin HY, Chang CY, Liu YC (2006a). Comparisons on the antioxidant properties of fresh, freeze-dried and hot-air-dried tomatoes. Journal of Food Engineering 77(3):478-485.

Chang Q, Zuo Z, Chow MS, Ho WK (2006b). Effect of storage temperature on phenolics stability in hawthorn (Crataegus pinnatifida var. major) fruits and a hawthorn drink. Food Chemistry 98(3):426430.
Chong CH, Law CL, Figiel A, Wojdyło A, Oziemblowski M (2013). Colour, phenolic content and antioxidant capacity of some fruits dehydrated by a combination of different methods. Food Chemistry 141(4):3889-3896.

Ciurzyńska A, Lenart A (2011). Freeze-drying-application in food processing and biotechnology-a review. Polish Journal of Food and Nutrition Sciences 61(3):165-171.

Coklar H, Akbulut M (2017). Anthocyanins and phenolic compounds of Mabonia aquifolium berries and their contributions to antioxidant activity.Journal of Functional Foods 35:166-174.

Çoklar H, Akbulut M (2016a). Alç (Crataegus orientalis) meyvesinin antioksidan aktivitesi ve fenolik bileşiklerinin ekstraksiyonu üzerine farkh çözgenlerin etkisi [Effect of different solvents on extraction of phenolic compounds and antioxidant activity of hawthorn (Crataegus orientalis) fruits].Derim 33(2):221-232.

Çoklar H, Akbulut M (2016b). Olgunlaşma ile alı̧ (Crataegus orientalis) meyvesinin antioksidan aktivite, toplam fenolik madde ve fenolik profilindeki değģim [The change in antioxidant activity, total phenolic content and phenolic profile of hawthorn (Crataegus orientalis) fruit with maturity]. FruitScience 3(2):30-37.

Edwards JE, Brown PN, Talent N, Dickinson TA, Shipley PR (2012). A review of the chemistry of the genus Crataegus. Phytochemistry 79:5-26.

Froehlicher T, Hennebelle T, Martin-Nizard F, Cleenewerck P, Hilbert JL, Trotin F, Grec S (2009). Phenolic profiles and antioxidative effects of hawthorn cell suspensions, fresh fruits, and medicinal dried parts. Food Chemistry 115(3):897-903.

Gao QH, Wu CS, Wang M, Xu BN, Du LJ (2012). Effect of drying of jujubes (Ziziphusjujuba mill.) on the contents of sugars, organic acids, $\alpha$ tocopherol, $\beta$-carotene, and phenolic compounds. Journal of Agricultural and Food Chemistry 60(38):9642-9648.

García-Mateos R, Ibarra-Estrada E, Nieto-Angel R (2013a). Antioxidant compounds in hawthorn fruits (Crataegus spp.) of Mexico. Revista Mexicanade Biodiversidad84(4):1298-1304.

García-Mateos R, Aguilar-Santelises L, Soto-Hernández M, Nieto-Angel R (2013b). Flavonoids and antioxidant activity of flowers of Mexican Crataegusspp. Natural Product Research 27(9):834836.

Gundogdu M, Ozrenk K, Ercisli S, Kan T, Kodad O, Hegedus A (2014). Organic acids, sugars, vitamin $\mathrm{C}$ content and some pomological characteristics of eleven hawthorn species (Crataegus spp.) from Turkey. Biological Research 47(1):21-26.

Jing Y, Chen JF, Zhao YY, Mao LC (2010). Effects of drying processes on the antioxidant properties in sweet potatoes. Agricultural Sciences in China 9(10):1522-1529.

Joshi A, Rupasinghe H, Khanizadeh S (2011). Impact of drying processes on bioactive phenolics, vitamin $\mathrm{C}$ and antioxidant capacity of red-fleshed apple slices.Journal of Food Processing and Preservation 35(4):453-457.

Krokida MK, MaroulisZB, Saravacos GD (2001). The effect of the method of drying on the colour of dehydrated products. International Journal of Food Scienceand Technology 36(1):53-59.

Kumar D, Arya V, Bhat ZA, Khan NA, Prasad DN (2012). The genus Crataegus: Chemical and pharmacological perspectives. Revista Brasileirade Farmacognosia 22(5):1187-1200. 
456

Kwok B, Hu C, Durance T, Kitts D (2004). Dehydration techniques affect phytochemical contents and free radical scavenging activities of Saskatoon berries (Amelanchier alnifolia nutt.). Journal of Food Science 69(3):122-126.

Liu P, Yang B, Kallio H (2010). Characterization of phenolic compounds in Chinese hawthorn (Crataegus pinnatifida Bge. var. major) fruit by high performance liquid chromatography-electrospray ionization mass spectrometry. Food Chemistry 121(4):1188-1197.

Maskan M (2001). Kinetics of colour change of kiwifruits during hot air and microwave drying. Journal of FoodEngineering 48(2):169-175.

Mejia-Meza E, Yanez J, Remsberg C, Takemoto J, Davies N, Rasco B, Clary C (2010). Effect of dehydration on raspberries: Polyphenol and anthocyanin retention, antioxidant capacity, and antiadipogenic activity. Journal of Food Science 75(1):5-12.

Miletić N, Mitrović O, Popović B, Nedović V, Zlatković B, Kandić M (2013). Polyphenolic content and antioxidant capacity in fruits of plum (Prunus domestica L.) cultivars 'Valjevka' and 'Mildora' as influenced by airdrying.Journal of Food Quality 36(4):229-237.

Mohd-Zainol M, Abdul-Hamid A, Abu-Bakar F, Pak-DekS (2009). Effect of different drying methods on the degradation of selected flavonoids in Centella asiatica. International Food Research Journal 16:531-537.

Nabavi SF, Habtemariam S, Ahmed T, Sureda A, Dagiia M, SobarzoSánchez E, Nabavi SM (2015). Polyphenolic composition of Crataegus monogyna Jacq.: From chemistry to medical applications. Nutrients 7(9):7708-7728.

ReR, Pellegrini N, Proteggente A, Pannala A, YangM, Rice-Evans C (1999). Antioxidant activity applying an improved abts radical cation decolorization assay. Free Radical Biology and Medicine 26(9):12311237.

Rice-Evans C, Miller N, Paganga G (1997). Antioxidant properties of phenolic compounds. Trends in Plant Science 2(4):152-159.

Sagar V, Kumar PS (2010). Recent advances in drying and dehydration of fruits and vegetables: A review. Journal of Food Science and Technology $47(1): 15-26$.
Shofian NM, Hamid AA, Osman A, Saari N, Anwar F, Pak Dek MS, Hairuddin MR (2011). Effect of freeze-drying on the antioxidant compounds and antioxidant activity of selected tropical fruits. International Journal of MolecularSciences 12(7):4678-4692.

Singleton V, Rossi JA (1965). Colorimetry of total phenolics with phosphomolybdic-phosphotungstic acid reagents. American Journal of Enology and Viticulture 16(3):144158.

Sogi DS, Siddiq M, Dolan KD (2015). Total phenolics, carotenoids and antioxidant properties of Tommy Atkin mango cubes as affected by drying techniques. LWT-Food Science and Technology 62(1):564 568.

Vega-Mercado H, Góngora-Nieto MM, Barbosa-Cánovas GV (2001). Advances in dehydration of foods. Journal of Food Engineering 49(4):271-289.

Wen L, Guo X, Liu RH, You L, Abbasi AM, Fu X (2015). Phenolic contents and cellular antioxidant activity of Chinese hawthorn Crataeguspinnatifida. Food Chemistry 186:54-62.

Wojdyło A, Figiel A, Lech K, Nowicka P, Oszmiański J (2014). Effect of convective and vacuum-microwave drying on the bioactive compounds, color, and antioxidant capacity of sour cherries. Food and Bioprocess Technology7(3):829-841.

Wojdyło A, Figiel A, OszmianskiJ (2009). Effect of drying methods with the application of vacuum microwaves on the bioactive compounds, color, and antioxidant activity of strawberry fruits. Journal of Agricultural and Food Chemistry 57(4):1337-1343.

Yanyang X, Min Z, Mujumdar AS, Le-qun Z, Jin-cai S (2004). Studies on hot air and microwave vacuum drying of wild cabbage. Drying Technology 22(9):2201-2209.

Zhang Z, Chang Q, Zhu M, Huang Y, Ho WK, Chen ZY (2001). Characterization of antioxidants present in hawthorn fruits. The Journal of Nutritional Biochemistry 12(3):144-152. 